Published by the University of KwaZulu-Natal https://journals.ukzn.ac.za/index.php/JICBE (C) Creative Commons With Attribution (CC-BY) Journal of Inclusive cities and Built environment. Vol. 2 Issue 1

How to cite: I.Chirisa and P. Mazanhi. 2022. Systems Connectivity for Sound Urban Policy Creation and Enhancement: Exploring Rural-Urban Interdependencies and Linkages for Inclusive Cities. Conference Proceedings for International Symposium on Inclusive-Cities: Achieving Inclusive Cities Through A Multidisciplinary Approach, 2021 28-30 June. Journal of Inclusive cities and Built environment. Vol. 2 Issue 1, Pg 17-20.

\title{
SYSTEMS CONNECTIVITY FOR SOUND URBAN POLICY CREATION AND ENHANCEMENT: EXPLORING RURAL-URBAN INTERDEPENDENCIES AND LINKAGES FOR INCLUSIVE CITIES
}

\section{By I.Chirisa and P. Mazanhi}

Published 31 January 2022

\begin{abstract}
This article is based on a study that investigated and examined the relevance of rural-urban linkages towards sustainable and inclusive development for both cities and rural areas. It argues that rural-urban linkages have great potential in facilitating sustainable development when harnessed and supported. The old definitive notion of rural and urban areas separated the two as distinct and independent regions. This led to biased policy initiatives towards urban development without consideration of the interdependencies between the two regions. The article is based on a desktop study involving the interrogation of literature and documents extracted from Google scholar, Ebsco and websites with news and policies and related material for data analysis. Emerging from the study are three main observations, that rural-urban linkages have huge potential that can help improve development; if not managed well, they can be manipulative and beneficial to one side and active participation in decision-making and implementation paves way for a sustainable future. It concludes that an in-depth understanding of these linkages can help harness the potential benefits that emanate from the rural-urban relationship. Policy recommendations are given that encourage inclusive city development rather than the separationist approach that dissects the existing rural-urban linkages.
\end{abstract}

KEY WORDS Sustainable development, Inclusivity, Poverty, Rural-urban linkages, Development policy.

Innocent Chirisa: University of Zimbabwe, Harare, Zimbabwe. University of the Free State, Bloemfontein, South Africa Patience Mazanhi: University of Zimbabwe, Harare, Zimbabwe 


\section{INTRODUCTION}

Urban and rural areas' linkages are increasing and the interconnectivity has moved from distinctive dichotomy and separation to highly integrated systems linked through various flows [9]. Transformations taking place in the rural areas and the expansive urbanisation in most cities should not be countered separately. This is a result of the existing mutually reinforcing linkages process that tend to tighten the bonds between spatial places and fosters urban and rural connectivity [6]. Livelihoods for people in rural areas are no longer dependent on rural resources but have crossed the spatial borders to urban areas, which in turn rely on rural areas for their survival [2].

The article examines the relevance of rural-urban linkages towards sustainable and inclusive development for both cities and rural areas. It argues that ruralurban linkages have great potential in facilitating sustainable development when harnessed and supported. Emerging from the study are three main observations, that rural-urban linkages have huge potential that can help improve development; if not managed well, they can be manipulative and beneficial to one side and; active participation in decision-making and implementation paves way for a sustainable future.

\section{RESULTS}

Rural-urban linkages reveal the notion of complementarity in the flow and movement of people, goods, technology and even information and these are further brought together in a web of complex dynamism, environmental synergies, and social changes. The existence of such complexity demands a move away from defining rural and urban areas as different and separate and the policies formulated should bring to harmony the two. A problem in the rural areas, if not addressed well, becomes a problem and consequence in urban areas. Thus, inclusive development is crucial in ensuring balanced development between the two areas.

\section{CASE STUDIES}

The following case studies have been selected to view existing rural-urban linkages and understand experiences from other nations to borrow lessons on how these linkages can be taken advantage of locally.

\subsection{VIETNAM}

Vietnam is a Southeast Asian country that is popular for its rivers, beaches and bustling cities [10]. The rapid urbanisation taking place globally is also evident in Vietnam's rural and urban regions. Together with industrialization in the country, urbanisation is concretizing rural-urban linkages. This has seen the interconnectedness in the labour market as rural workers can now easily commute to their workplaces in various industrial sites [5]. Unlike the developing world, the industrial and economic sector in Vietnam is well developed and a few disparities can be noticed between rural and urban areas. There is very minimum rural-urban migration. Development efforts in the country tend to nurture local development and livelihoods strategies. Each village develops according to the available resources it has and this enhances specialisation that promotes inter-trade activities between areas. Farming is a primary activity that has been kept alive within the country as it is the source of food and the drive for food systems and markets [10]. With the improved transportation systems, trade has been enhanced and increasing short-distance migration between ruralurban areas. However, climate change has been a detrimental challenge to the Mekong Delta and other river channels where food production was concentrated. The floods, droughts and unpredictable severe weather conditions are affecting food production in the region [5].

\section{$3.2 \quad$ ZIMBABWE}

Rural-urban linkages in Zimbabwe are quite noticeable especially the existing interactions with the major cities, such as Harare, Mutare and Masvingo. Before independence, there was a separation of rural and urban areas into distinct and standalone places. However, upon the attainment of independence, there was unrestricted interaction between rural and urban areas [8]. Gone are the days when the rural areas were characterised by extreme poverty, even in the urban areas, a lot of people are suffering from poverty. Harare has the highest number of poverty-stricken residents and this has also affected remittances to the rural areas. As the food crisis worsened in the urban areas, a lot of people now consider ploughing their fields in the rural areas for food provision and this has been leveraging food security [3]. The ties existing between rural and urban areas in Zimbabwe are intact and better methods need to be explored to make the interdependencies more beneficial [4]. With the increasing economic crises, exacerbated by the COVID-19 pandemic, owning a piece of land for agricultural purposes is one way towards urban food security. And this demands intact rural and urban relationships.

\section{DISCUSSION}

The existing spatial imbalances between the rural and urban areas are becoming complicated by the day as it is no longer the usual divide separating poor, marginalised and disconnected rural areas from the well-connected, rich and central urban centres [1]. Rural and urban areas are distinct places separated by geographical locations and this differentiates the livelihood sources and strategies for the areas. While it is a common feature that rural areas are characterized as poorer than urban areas, some rural areas are prospering more than urban areas [9]. Some settlement areas tend to have a geographical advantage of large resource endowments that make them prosper compared to other areas. This often leads to uneven socioeconomic development with the more developed becoming the core and the less developed areas, the peripheries. However, this tends to change with time due to increasing rural-urban interdependencies that change the traditional definition of 'urban' and 'rural' spaces [2].

Existing spatial inequalities are to a greater extent caused by the separationist definitive approach to rural and urban areas. This views rural and urban areas as distinct areas and has led to segregationist development policies 
that tend to put much focus on the urban centre [9]. Failure to acknowledge the existing and growing rural-urban linkages has led to massive inequalities between rural and urban areas. [5] highlights agriculture as one popular example that shows the interdependence and linkage between the rural and urban areas. Agriculture is primarily practised in the rural areas and complemented by manufacturing and service industries that are dominant in the urban areas [9]. Most markets food markets in urban areas rely on agricultural produce from the rural areas, which benefit from profits obtained in selling their produce. This shows an existing bonding between the rural and urban areas, an unbreakable interdependency and complementary relationship between the two.

However, though this relationship practically exists, there is a lag in the governance and policy development arena that tends to view the two separately in development initiatives [9]. This has led to inequalities in development between the rural and urban divide. Appreciating the existing complementary relationship can help minimize spatial differences. The rural areas are highly endowed with natural resources and an ecosystem that is highly-priced for sustainability and smart city development [9]. On the other hand, the urban area has the social services that are absent in the rural area and most of them are less economic if provided in the rural areas. Also, the existing ruralurban migration is evidence enough that the two divides depend on each other. The failure to address the problems of one, the effects may be felt by the other [11]. For example, the failure to solve livelihood challenges in the rural areas results in the flocking of multitudes to the urban areas, which exacerbates unemployment rate and informality challenges.

\section{CONCLUSIONS}

Inclusive cities demand a change of analytical lens that see rural and urban areas as separate and distinct localities yet well-connected. There is a need to flow according to the current when considering development rather than oppose the reality on the ground. Development policies should adopt the reality of the existence of ruralurban linkages to avoid continuous compartmentalizing rural-urban categories. Rural and urban areas coexist and the residents in either of the places and local organizations have become intertwined by the social and economic exchanges between these areas. Even where there are non-existent linkages, it is even imperative to create the networks and connections between the two spatially separate groups. Bringing these two places together brings benefit to the development of both areas and the stronger the linkages, the greater the chances of economic growth and prosperity. There is a need for social cohesion that unifies people and that does not create an environment where the urbanites feel superior to the rural dwellers. An understanding that social structures need each other for development brings together the forces of development that target the common good. Ensure active participation of all stakeholders in developing workable policies and strategies. 


\section{REFERENCES}

Akkoyunlu, S.: The Potential of RuralUrban Linkages for Sustainable Development and Trade. Working Paper Number 2013/37. Swiss National Centre of Competence in Research (2013).

Berdegué J. A., Proctor F. J. and Cazzuffi C. Inclusive Rural-Urban Linkages. Working Paper Series $N^{\circ}$ 123. Working Group: Development with Territorial Cohesion. Territorial Cohesion for Development Program. Rimisp,

Santiago, Chile (2014).

Crush, J. and Caesar, M. Food

Remittances: Rural-Urban Linkages and Food Security in Africa. IIED (2017).

Djurfebdt, A. A. Virtuous and Vicious Cycles in Rural-Urban Linkages: Cases from Zimbabwe. Africa Review 4(2), 36156 (2012).

Hatcher, C. Rural-Urban Linkages in the Context of Sustainable Development and Environmental Protection. Global Land Outlook Working Paper. UNCCD (2017).

Mylott, E. Urban-Rural Connections: A Review of the Literature (2009).

OECD. Megatrends: Building Better Futures for Regions, Cities and Rural Areas. OECD Regional Development Ministerial, Athens (2019).

Potts, D. and Mutambwa, C. RuralUrban Linkages in Contemporary Harare: Why Migrants Need their Land. Journal of Southern African Studies 16(4), 677-698 (2007).

Stenberg, F. Rural-Urban Linkages: An Urban Perspective. Document Number128. Working Group:

Development for Territorial Cohesion for Development Project, Rimisp, Santiago, Chile (2014).

Thanh, H. X., Anh, N. and Tacoli, C. Livelihood Diversification and RuralUrban Linkages in Vietnam's Red River Delta (2005).
UNHABITAT. Rural-Urban Linkages: Guiding Principles. Framework for Action to Advance Integrated Territorial Development. UNHABITAT (2019). 